\title{
Retrospective study of 67 cases of secondary pars plana posterior capsulotomy
}

\author{
N MASHHOUDI' AND J L PEARCE ${ }^{2}$ \\ From the 'Birmingham and Midland Eye Hospital, Church Street, Birmingham B3 2NS, and ${ }^{2}$ Bromsgrove \\ General Hospital, All Saints Road, Bromsgrove, Worcs B61 OBB
}

SUMmARY A technique of late pars plana posterior capsulotomy following extracapsular cataract extraction and posterior chamber lens implantation is described. The results and complications of 67 cases with an average follow-up period of approximately 14 months are reported. The incidence of cystoid macular oedema following this procedure was $2.9 \%$, with no incidence of retinal detachment. The procedure appears to be an acceptable method of treating a thickened posterior capsule, and in the absence of a neodymium YAG laser and in a small unit it could prove to be a reasonable substitute.

Extracapsular cataract extraction (first described by Jacques Daviel in 1753) combined with posterior chamber intraocular lens implantation is enjoying a resurgence of interest because of the reported reduction in the incidence of postoperative cystoid macular oedema and aphakic retinal detachment. ${ }^{2}$ The after cataract, which forms in the scaffolding of the posterior capsule, remnants of the anterior capsule, and lens matter, presents a special problem of management in the presence of a posterior chamber lens.

This paper reports on the pars plana approach to late posterior capsulotomy, which is performed in our unit as an outpatient procedure. The complications related to this procedure are recorded.

\section{Materials and methods}

\section{TECHNIQUE}

Secondary pars plana capsulotomy was described by Lindstrom and Harris ${ }^{3}$ and has been performed by Epstein in South Africa for many years.

In our department this procedure is performed on an outpatient basis with an operating microscope under local anaesthetic. A fine, sharp, self-sealing discission knife is essential to enable penetration of the sclera with minimal pressure. One of the authors (J.L.P.) has designed a micro needle knife for the procedure.

Anaesthesia is achieved by the following method: facial akinesia with $2 \%$ lignocaine plus $1 / 10000$

Correspondence to Mr N Mashhoudi, FRCS. adrenaline by Van Lint's method, and then a small bleb of the same local anaesthetic is lifted in the inferotemporal and superonasal quadrant of the bulbar conjunctiva. The superonasal anaesthetic is necessary to enable the surgeon to grip the globe with toothed forceps. An operating microscope is used with full sterile procedure. Full pupillary dilatation is effected by topical cyclopentolate $1 \%$ and/or phenylephrine $10 \%$. Eyelid retraction is with a Barraquer speculum, and corneal clarity is maintained with balanced salt solution (BSS) irrigation. Conjunctiva and Tenon's capsule are gripped in the superonasal quadrant, and the sclera is penetrated by the needle knife $3.75 \mathrm{~mm}$ from the limbus in the inferotemporal quadrant, with the initial penetration perpendicular to the sclera. The needle knife point is located in the pupil and engages the posterior capsule from below or above, and a slit is cut in such a way that it does not extend beyond the optic area of the intraocular lens.

At the end of the operation injections below Tenon's capsule of antibiotics and long-acting steroids are routinely prescribed. Patients are reexamined one hour postoperatively on a slit-lamp biomicroscope and discharged home on topical steroids and mydriatics.

\section{PATIENTS' RECORDS}

The records of 77 patients who had undergone extracapsular cataract extraction by one of the authors (J.L.P.) and subsequent pars plana posterior capsulotomy with a minimum six-month follow up (mean 14 months) were reviewed. Of these patients 
58 attended for detailed examination for the purposes of this study.

Records of all cases were studied. Their visual acuities were measured at $6 \mathrm{~m}$ on a Snellen's chart, refraction was performed in cases with visual acuity less than 6/6, slit-lamp biomicroscopy was performed, contact lens, three-mirror funduscopy, and indirect ophthalmoscopy were routinely performed, and fluorescein angiography was carried out on those with clinically equivocal macular disease.

\section{Results}

Fifty-eight patients (64 eyes) were included in this study (six bilateral cases), and three of them had a second procedure performed (total of 67 cases). The age range of the patients was 18-90 years (average 67). Table 1 shows the age distribution and Table 2 shows the type of cataract.

Table 1 Age distribution of 58 patients in study

\begin{tabular}{lc}
\hline Age group & Number \\
\hline $10-19$ & 1 \\
$20-29$ & 1 \\
$30-39$ & 1 \\
$40-49$ & 3 \\
$50-59$ & 7 \\
$60-69$ & 15 \\
$70-79$ & 20 \\
$80-90$ & 10 \\
Total & 58 \\
\hline
\end{tabular}

Table 2 Type of cataract in 64 eyes in study

\begin{tabular}{lc}
\hline Type of cataract & Number \\
\hline Senile & 49 \\
Familial & 5 \\
Traumatic & 4 \\
Congenital & 2 \\
Usher's syndrome & 2 \\
Retinitis pigmentosa & 1 \\
Complicated & 1 \\
Total & 64 \\
\hline
\end{tabular}

Table 3 Type of intraocular lens implanted

\begin{tabular}{lc}
\hline Type of intraocular lens & Number \\
\hline Pearce tripod posterior chamber lens & 47 \\
Pearce Y loop posterior chamber lens & 7 \\
Binkhorst 4 loop iris clip lens & 2 \\
Boberg-Ans iris clip lens & 1 \\
Simco anterior chamber lens & 1 \\
Choyce anterior chamber lens & 1 \\
Others & 1 \\
No intraocular implant & 4 \\
Total & 64 \\
\hline
\end{tabular}

All but one of the patients underwent this procedure because of an opaque posterior capsule. The one exception had uniocular diplopia, which was eliminated by capsulotomy. The average follow-up period was 14 months (minimum six months and maximum 54 months).

Sixty of the 64 eyes had intraocular implants. Table 3 shows the type of intraocular lens implanted. Two of the 64 eyes had primary posterior capsulotomy at the time of cataract extraction. The time period between cataract extraction and late pars plana capsulotomy varied from eight months to 68 months (average 30 months).

The precapsulotomy visual acuity is shown in Table 4. The postcapsulotomy corrected visual acuity achieved at the time of the survey is shown in Table 5. Table 6 shows the causes of a corrected

Table 4 Visual acuity before pars plana posterior capsulotomy

\begin{tabular}{lc}
\hline Precapsulotomy visual acuity & Percentage \\
\hline 6/6 or better* & (one case) \\
6/12 or better & $15 \cdot 5$ \\
6/24 or better & $36 \cdot 5$ \\
Less than $6 / 24$ & $46 \cdot 5$
\end{tabular}

*This case had uniocular diplopia due to capsular wrinkling, which was eliminated with capsulotomy.

Table 5 Visual acuity after pars plana posterior capsulotomy

\begin{tabular}{ll}
\hline $\begin{array}{l}\text { Corrected visual acuity achieved } \\
\text { at the time of survey (no exclusion) }\end{array}$ & Percentage \\
\hline $6 / 6$ or better & $37 \cdot 5$ \\
$6 / 12$ or better & $37 \cdot 5\}=75$ \\
$6 / 24$ or better & $11 \cdot 0$ \\
Less than $6 / 24$ & $14 \cdot 0$ \\
\hline
\end{tabular}

Table 6 Causes of low visual acuity

\begin{tabular}{ll}
\hline $\begin{array}{l}\text { Causes of a corrected visual acuity } \\
\text { less than 6/9 }\end{array}$ & Number \\
\hline Amblyopia & 4 \\
Cystoid macular oedema & 2 \\
Diabetic retinopathy & 4 \\
Low grade uveitis & 1 \\
Myopic degeneration & 2 \\
Optic atrophy & 2. \\
Pigment deposit on intraocular lens & 1 \\
Retinal branch vein occlusion & 2 \\
Retinitis pigmentosa & 1 \\
Retinal branch artery occlusion & 1 \\
Senile macular degeneration & 6 \\
Thickened posterior capsule & 6 \\
Usher's syndrome & 2 \\
Vitreous membrane & 1 \\
\hline
\end{tabular}


Table 7 Visual acuity after pars plana posterior capsulotomy

\begin{tabular}{lc}
\hline $\begin{array}{l}\text { Corrected visual acuity achieved excluding } \\
\text { unrelated posterior pole pathology }\end{array}$ & Percentage \\
\hline $6 / 6$ or better & $60 \cdot 50$ \\
$6 / 12$ or better & $26 \cdot 50\}=87$ \\
$6 / 24$ or better & $10 \cdot 50$ \\
Less than $6 / 24$ & $2 \cdot 50$ \\
\hline
\end{tabular}

Table 8 Complications of pars plana posterior capsulotomy in 67 cases

\begin{tabular}{ll}
\hline Complications & Number \\
\hline Transient rise in IOP & 7 \\
Transient uveitis & 4 \\
Vitreous haemorrhage (cleared) & 3 \\
Displacement of intraocular lens & 3 \\
Vitreous in anterior chamber & 2 \\
Cystoid macular oedema & 2 \\
Retinal detachment/dialysis & 0 \\
Endophthalmitis & 0 \\
\hline
\end{tabular}

visual acuity of less than 6/9. The corrected visual acuity achieved apart from unrelated posterior pole pathology is shown in Table 7. Table 8 shows the complications attributable to the procedure.

\section{Discussion}

Although there is sufficient evidence that the presence of an intact posterior capsule reduces the incidence of cystoid macular oedema and rhegmatogenous retinal detachment, ${ }^{12}$ controversy remains on the incidence of complications after elective primary capsulotomy at the time of cataract extraction and of late capsulotomy, which would be required in approximately one-third of extracapsular cataract extractions after three years.

With a pars plana approach to late capsulotomy discission of the posterior capsule without rupturing the anterior hyaloid face would be impossible, but the presence of a close contact and probable seal between the capsulotomy margins and the optic part of the posterior chamber lens could prevent vitreous herniation into the anterior chamber and reduce vitreoretinal complications. ${ }^{3}$ In our experience posterior capsulotomy through the anterior segment is likely to decenter the posterior chamber lens and bring vitreous into the anterior chamber and to the wound.

The entry hole for late pars plana capsulotomy is necessarily made in the ciliary epithelium, but technical error may also cause peripheral retinal perforation or dialysis. Newly formed tissue may grow into the vitreous as a result of perforation, causing localised vitreoretinal traction. The latter effect may be reinforced by vitreous haemorrhage, however slight, that may occur at the time of operation. ${ }^{4}$ It is mandatory to avoid contact with the pars ciliaris of the ciliary body at the time of penetration of the globe, and this complication can be reduced by making the initial incision perpendicular to the sclera. There is a risk of endophthalmitis if organisms on the conjunctival surface are carried into the vitreous cavity.

In our study two of 67 cases $(2.9 \%)$ who underwent late pars plana posterior capsulotomy approximately 13 and 17 months after extracapsular cataract extraction and posterior chamber lens implantation developed cystoid macular oedema. The first patient achieved a corrected visual acuity of $6 / 6$ immediately after capsulotomy, but this reduced subsequently to $6 / 18$ due to cystoid macular oedema. The visual acuity in the second case was $6 / 60$ immediately after capsulotomy because of vitreous haemorrhage and remained at this level despite the vitreous clearing, a result of florid cystoid macular oedema. We presume these two cases of cystoid macular oedema were due to capsulotomy, though the prior capsular opacity precluded a clear view of the macula preoperatively. This figure compares with $3.5 \%$ incidence of cystoid macular oedema after late posterior capsulotomy with the limbal approach reported by Livernois and Sinskey. ${ }^{5}$

The incidence of cystoid macular oedema following late posterior capsulotomy with the non-invasive method of neodymium YAG laser has not been fully studied yet, but indications suggest a figure of around $2 \%$ (Harris, personal communication 1984).

Of the three cases of vitreous haemorrhage all cleared completely. In one patient the visual acuity dropped to $6 / 60$ owing to cystoid macular oedema (see above); the remaining two achieved a corrected visual acuity of $6 / 6$ and $6 / 12$.

There were six cases of rethickened posterior capsule and/or inadequate central gap. Their visual acuities were between $6 / 12$ and $6 / 18$. They may have been improved with further capsulotomies.

Except for one case of vitreous membrane formation other complications in our study were transient, and slight displacement of intraocular lenses at most requiring only marginal change of optical correction. The case of vitreous membrane formation had a secondary insertion of anterior chamber lens and late capsulotomy (separate procedures) in our department following extracapsular cataract extraction in another hospital, and we could not verify the time of vitreous veil formation.

There was no incidence of retinal detachment, and although our study does not include enough patients to draw a definitive conclusion it may suggest that 
delaying discission for capsular thickening may reduce retinal complications. McPherson et al. ${ }^{6}$ in a study of 27 eyes with retinal detachment after extracapsular cataract extraction and late posterior capsulotomy, considered that the interval between cataract extraction and discission had a significant effect on the extent of retinal detachment and recovery of visual acuity after retinal detachment repair.

In our experience pars plana late posterior capsulotomy has proved to be a satisfactory method of dealing with a thickened posterior capsule after posterior chamber lens implantation. It provides easy access to the posterior capsule and also reduces the risk of disrupting the capsular fixation of the lens. In the absence of non-invasive but expensive instrumentation (neodymium YAG laser) this procedure could prove to be a reasonable substitute.
We thank outpatient nursing staff of the Bromsgrove General Hospital for their help in conducting the survey and Miss P Quinn and Mrs C Rawlins for their secretarial assistance.

\section{References}

1 Jaffe NS, Clayman HM, Jafee MS. Cystoid macular oedema after intracapsular and extracapsular cataract extraction with and without an intraocular lens. J Am Acad Ophthalmol 1982; 89: 25-9.

2 Drews RC. The Pearce tripod posterior chamber intraocular lens, an independent analysis of Pearce's results. J Am Intraocular Implant Soc 1980; 6: 259-62.

3 Lindstrom RL, Harris WS. Management of posterior capsule following posterior chamber lens implantation. J Am Intraocular Implant Soc 1980; 6: 255-8.

4 Schepens CL. Retinal detachment and allied diseases. Philadelphia: Saunders, 1983; 1: 54.

5 Livernois R, Sinskey RM. Complications of late capsulotomy. J Am Intraocular Implant Soc 1981; 7: 242-3.

6 McPherson AR, O'Malley RE, Bravo J. Retinal detachment following late posterior capsulotomy. Am J Ophthalmol 1983; 95: 593-7. 